\title{
Optimization on Decision Making Driven by Digitalization
}

\author{
Steffen Hoßfeld \\ University of Latvia, Riga, Latvia
}

\begin{abstract}
The content of this paper refers to the global trend of digitalization and its implications on decision making. The question: will digitalization improving decisions in organizations be a relevant topic for all organizations? Digitalization is currently the key driver for change in business and organizations. Affected is everything, from market structures to customer behaviour over supply chain and production itself. Internal processes have opportunities for a new design, and production and logistics are possible to redesign. This massive game changing opportunity has to be steered by management and hence management decisions are a must while this transition phase; furthermore, decisions will influence this transition but decisions itself are also affected. The paper is based on a theoretical research, analysing different decision models. In the first part of the paper, typical decision models will be discussed; a rational model with first ideas of the neoclassical economists (e.g. Adam Smith or Max Weber) and scientific approaches of Pascal and de Fermat or Bernoulli, mainly focused on agents which maximize their utility. Further developed by von Neumann and Morgenstern (2004), economic decisions seem to be a strong rational and mathematical process to find utility maximization. This rational model is illustrated on the one hand to explain the traditional way and has a view on the model of homo oeconomicus. On the other hand, a strong emotional influence on decision making is obvious, because human beeings do not follow strict rational rules. In the second part of the paper, digitalization as one part of globalization will be analysed. Digitalization will change completely the business environment and the setup of organizations. New market structures, customer behaviour, and processes will change the entire operations of businesses. Then, the main discussion of the paper, the impacts of digitalization on decision making will show the trend toward the well-known model of homo oeconomicus, which is a common model in economics; but known with a lot of limitations. Automatization of processes will affect the decision process in organizations. This new decision making processes will be mainly automated in the future, hence an algorithm logic is required and enables the model of homo oeconomicus a revival, driven by machines. As a conclusion based on the above mentioned result, automated decisions will improve the result of decisions, because human emotions will not affect the decision making process anymore.
\end{abstract}

Keywords: decision making, globalization, digitalization, digitalization of decision making, homo oeconomicus, rational choice

\section{Introduction}

These days, two main trends are on the agenda of organizations: globalization and digitalization. The ongoing trend of globalization increased tremendously the complexity of business. This trend shows two

Steffen Hoßfeld, MBA, Department of Management, University of Latvia, Riga, Latvia.

Correspondence concerning this article should be addressed to Steffen Hoßfeld, Steffen Hoßfeld, Aspazijas Boulevard 5-327, Riga, LV-1050, Latvia. 
flipsides of a coin, opportunities, and challenges. Huge opportunities are a wider scope of a customer base and further possibilities of global sourcing. This variety of alternatives increased the complexity of an organization; decisions in today are more extensive than they were in the past, because the need for decisions in organisations was ever a complex procedure, but the quality of a decision was never so complicated but important than today. Based on this increased complexity, the need for information for these decisions is more important than ever. The new megatrend of digitalization supports the opportunities of globalization and will change decision models dramatically, because concentration of business is one part of this trend, a "winner takes it all" mentality is a digital phenomenon, e.g., the global success of Amazon, but who is the number two? The possibilities for organizations by increasing efficiency or designing a new business model are manifold. Machines already took over routine jobs, but in the new age, machines will communicate between each other and will independently optimize their production flow (Spath, 2013). For instance, in 2010, Google made the first driverless car test in California (Brynjolfsson \& McAfee, 2014). Digitalization and the trend toward "Big Data" support data collection and the usage of big data bases, either internally or externally. Hence, the attitude and process of decisions will be changed by these trends. Contemporary literature and research regarding decision making, have to re-evaluate the current status. Today's view on behavioural driven decision (human view) is very popular, discussed by Kahneman and Tversky (1974), e.g. the "prospect theory" or the "endowment effect"-well collected in their book "Thinking, Fast and Slow" (Kahneman, 2011).

Today's view on digitalization is eye opening, because it is not a temporary fashion, it will change the entire economy, every organization is affected in different ways of digitalization. Kondratieff's waves shows the evidence that in the last years the next step of Kondratieff's waves already started; about the year 2009/2010 (Wilenius, 2014), in the beginning of the financial crisis. Hence, a new era of business will start with the trend of the second machine age (Brynjolfsson \& McAfee, 2014). For a new era, a new type of decision making is necessary and this paper will analyse the current status of decision making in organizations and will discuss the new way of making decisions in the new era of intelligent machines. The view of decision making under the new paradigm of digitalization is a new perspective on decision making.

\section{Literature Review}

\section{Theoretical Foundation of Decision Making}

Decision theory is a wide area in science, with a long tradition. The first idea of decision theory reaches back over hundreds of years and is still relevant in the presence. Rational models were discussed from the neoclassical economists (e.g. Adam Smith or Max Weber) with a view on rational behaviour of agents which maximizes their utility - the homo oeconomicus. A more scientific approach of Pascal and de Fermat shows a calculation of probabilities and Bernoulli laid the foundation of risk science by examining random events. Further developed by von Neumann/Morgenstern economic behaviour in a strong rational and mathematical approach, decision making follows utility maximization. Today's view of decision theory as an interdisciplinary science (economics, psychology, sociology, philosophy, mathematics, computer science, and statistics) with different approaches is generally accepted (Buchanan \& O'Connell, 2006). One of the most popular is still the theory of games and economic behaviour (von Neumann \& Morgenstern, 2004). The theory of von Neumann and Morgenstern (2004) explains a rational behaviour of market participants (either consumers or entrepreneurs). Consumers strive for a maximum utility or satisfaction and entrepreneurs strive for maximum profits. Meanwhile, a wide area of mathematical approaches and models of rational theories were 
further developed on the foundation of von Neumann/Morgenstern theories. The opposite of the rational view is a behavioural view on decisions. In the late 1940s, Simon (1997) discussed the theory of bounded reality, which means a certain influence of human attitudes with not pure rational decisions. A deeper view in the psychology science shows that theories on behavioural economy are currently quite popular, because human behaviour is one part of organizational actions. In the 1970s, Kahneman and Tversky (1974) developed the prospect theory. The idea of the prospect theory is a human approach in decision making. The theory of Kahneman and Tversky (1974) demonstrates that market participants do not act as rational as assumed, i.e., by the theory of von Neumann and Morgenstern (2004). Depending on the used system of a human (system 1 or system 2), a choice is more emotional or more rational. The drivers of the emotional system have a different set up, hence, loss aversion and optimistic bias or overconfidence are important to understand in a decision making process and will be explained in detail.

Rational view. In the classical field of the economical view on decision theory, a rational, mathematical founded approach is discussed. The process of pure calculating to find a maximum of utility or profit is a typical rational procedure. First of all, an overview of the basic elements will enable a better view on the concept of a decision model. In Figure 1, the common structure of decision models is shown.

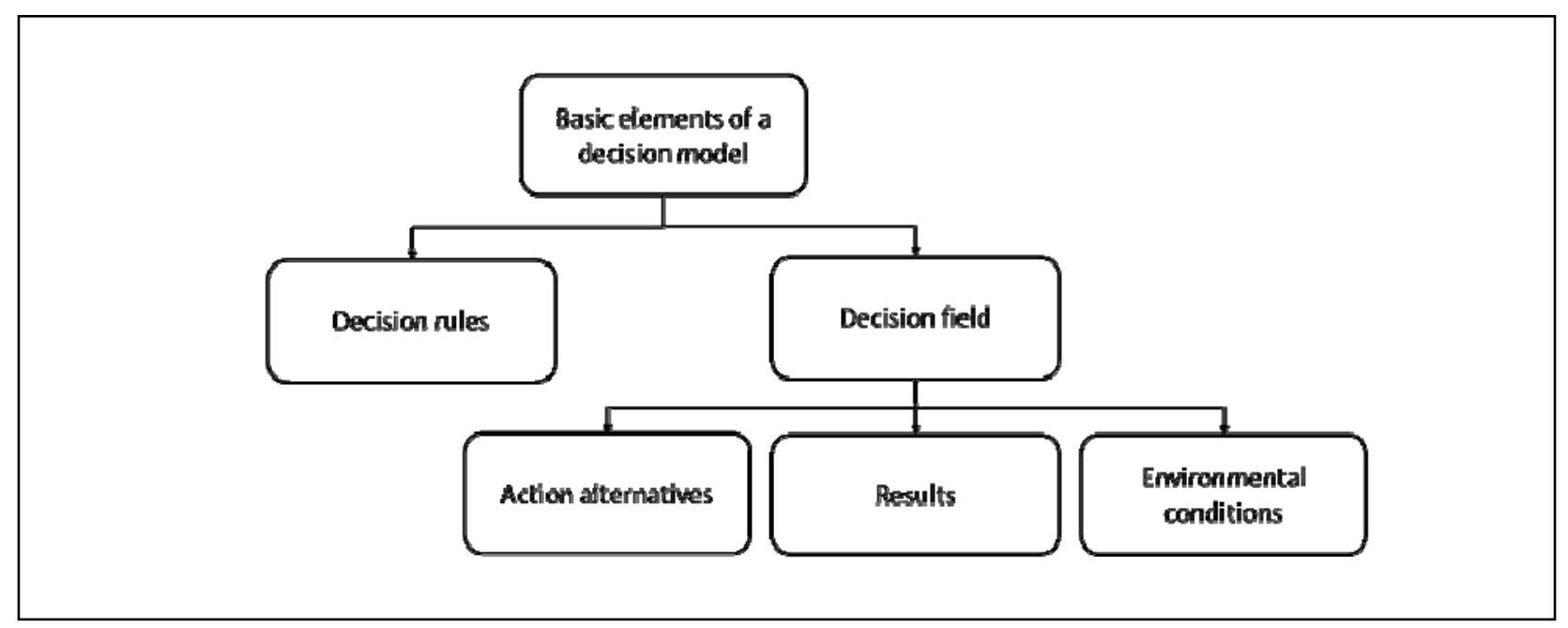

Figure 1. Basic Elements of a Decision Model. Source: Author's construction based on Bamberg, Coenenberg, and Krapp (2012).

In the dimensions of decision fields, the alternatives are very important to analyse. There is only a decision problem, if there are minimum two alternatives. Hence a determination of these alternatives must be reflected in the decision model. In the next step, an evaluation of these alternatives must be done. These consequences will lead to a result of the alternatives into the decision model. Important figures of the decision maker are defined as targets, these values are the result (Laux, Gillenkirch, \& Schenk-Mathes, 2014).

Key for a decision process is the potential prospect structures, this defines the type of a decison. Measures are not manipulable by the decision maker, these measures are called decision relevant data. These data are no variables of the decision maker. These characteristics are decision relevant environmental conditions. The illustration of Figure 2 (Laux et al., 2014) shows different environmental situations and a possibility of designing decision conditions. 


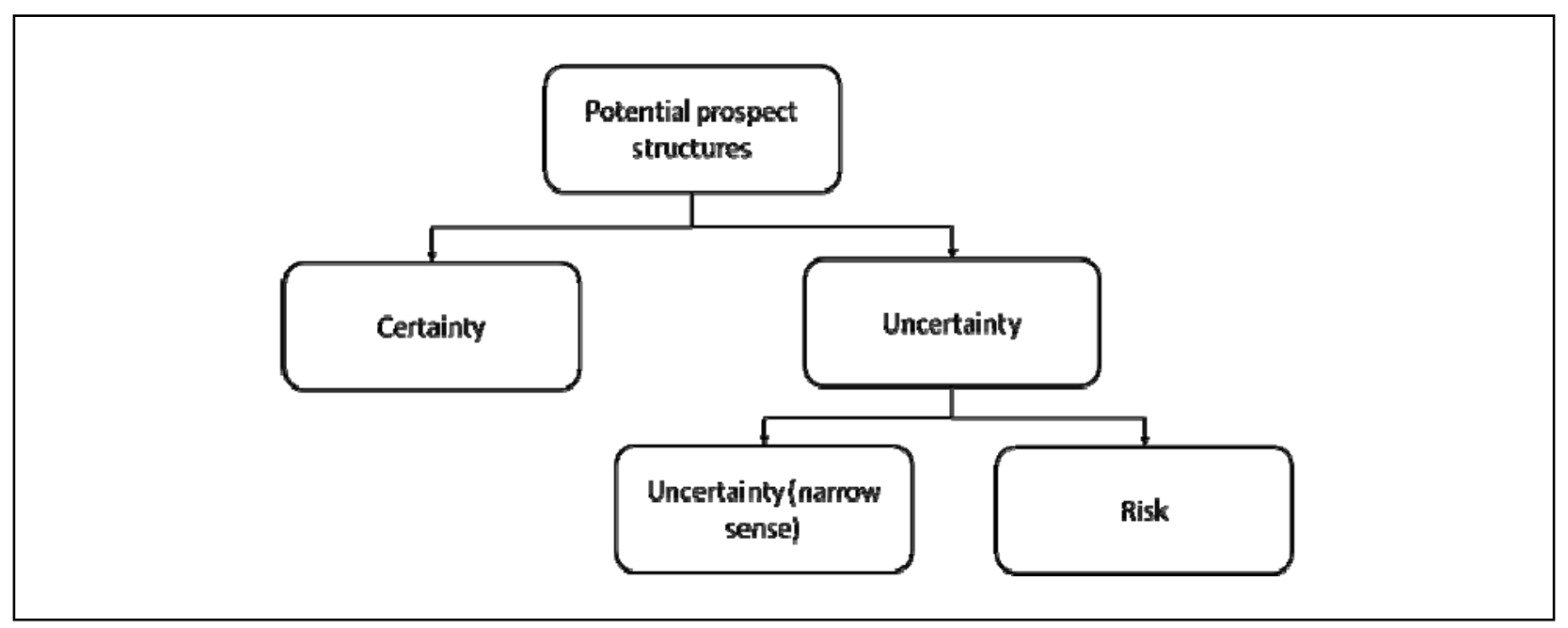

Figure 2. Structures of Environmental Conditions. Source: Author's construction based on Bamberg et al. (2012).

A decision structure under certainty means that the decision maker has the real condition of the alternatives, hence all relevant information for the decision is given. Therefore the result is known and alternatives are certain. In reality, quite often decision models are formed as models of decision under certainty, because the set up and the usage of this model type are easier to handle (Bamberg et al., 2012).

A decision structure under uncertainty means that the decision maker has minimum two possible alternatives, but not all relevant information for a decision is given. Therefore the result is not known and alternatives are uncertain. In the case of uncertainty, there are two more possibilities. Either for the decision maker, it's not possible to calculate a likelihood of conditions (uncertainty-narrow sense) or for the decision maker, the probability of occurrence of a condition is computable (risk) (Laux et al., 2014).

This differentiation of the environmental conditions is important to define; especially decision making in the context of globalization and digitalization. While globalisation creates a more complex world with an increase of uncertain decision structures, a more sophisticated model with an adopted process of decisions is a need for an organization. In terms of digitalization, a need for an algorithmic structure is necessary, computers need a mathematical logic in their system to calculate a result for a decision process.

Human view. Important developments in decision theory took place over the recent decades, though a trend to a behavioural approach was supported by psychological science. An outstanding contribution to the development of behavioural economies was made by Kahneman and Tversky (1974). A collection of their scientific contribution and analysis is made in the book "Thinking, Fast and Slow" (Kahneman, 2011). Describing decision theory with a strong psychological view makes decision more emotional than rational. Depending on the activated system in the mind, Kahneman (2011) named it system 1 and system 2.

- "System 1 operates automatically and quickly, with little or no effort and no sense of voluntary control" (Kahneman, 2011)

- Examples: answer of $2+2$ =?; drive on an empty road, orient the source of a sudden sound

- "System 2 allocates attention to the effortful mental activities that demand it, including complex computations. The operations of system 2 are often associated with the subjective experience of agency, choice, and concentration" (Kahneman, 2011)

- Examples: telling someone your mobile number, filling out a form, looking for a woman with white hair 
The human structure is based on usage of system 1, only if really necessary, system 2 is activated.

This concept of system 1 and system 2 set the basis for a human behaviour of decision making, which absolutely defers from a rational decision view. Continuing this idea, the question what prevents a rational decision answered with Kahneman and Tversky's (1974) prospect theory. The fact that lot of decisions have both elements, a risk of loss and an opportunity of gain, affects a decision to gamble or to deny. Focussing on loss aversion (Kahnemann \& Tversky, 1974) means people avoid losses while there is a huge opportunity to gain this particular option. As a result, people deny this option and this is controversial to a rational choice, with a pure calculation of probability. The "optimistic bias" means that chances for success are overestimated. Risks are undervalued or not in scope of the decision maker (Kahneman, 2011).

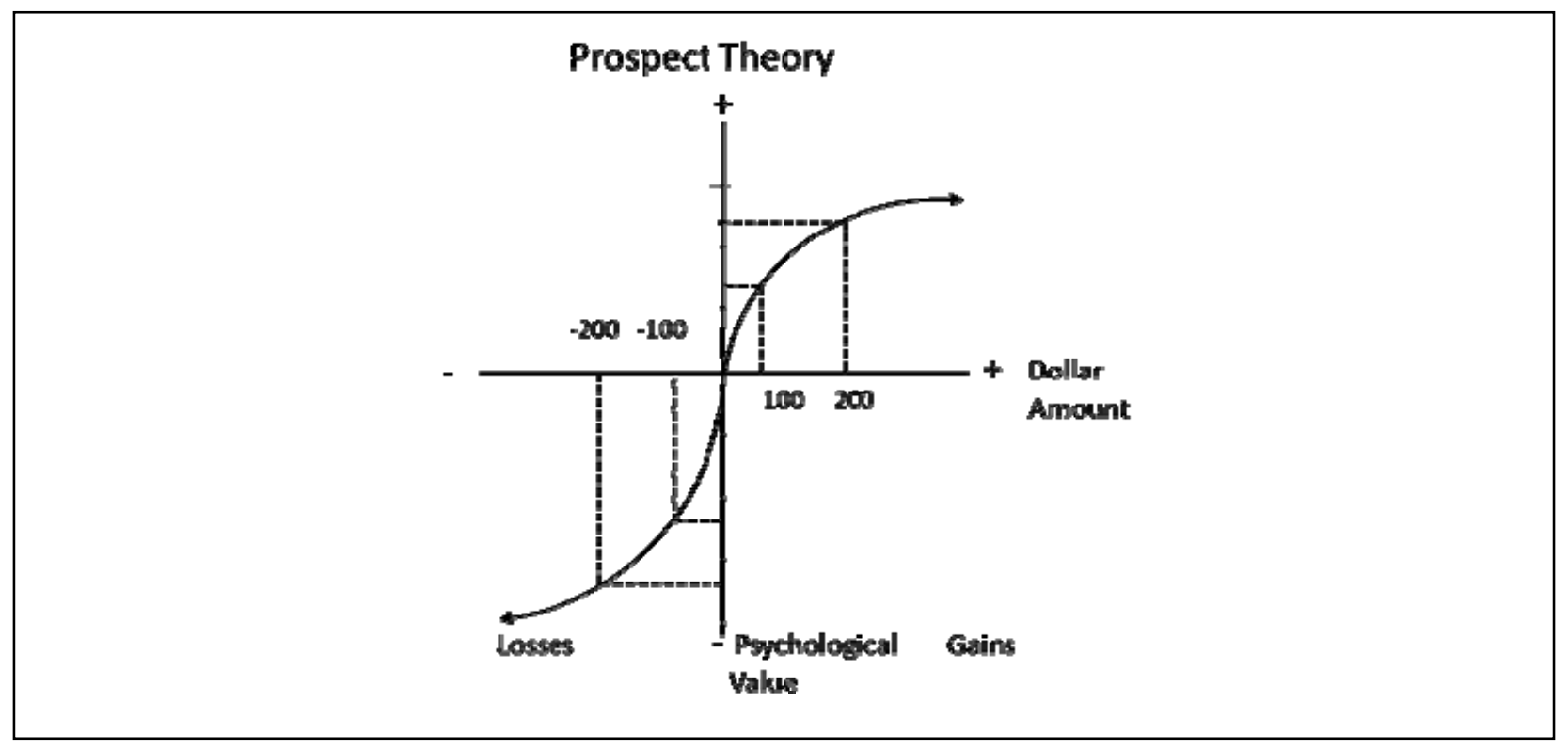

Figure 3. Prospect theory. Source: Author's construction based on Kahneman and Tversky (1974).

Figure 3 explains the loss aversion theory and as opposite to a rational decision, it's not a straight line. The chance of losses is moving the decision and also the chance of gains is moving the line, with a peak to losses.

The graph is showing the following effects:

- The psychological value of gains and losses as carriers of values (as opposite Bernoulli stated wealth as carrier of value)

- Reduced sensitivity for gains and losses

- The slope of the function changes at the reference point

- The response to losses is stronger than the response to corresponding gains (loss aversion)

- The two curves of the " $S$ " are not symmetrical

Prospect theory is only one topic raised in the context of behavioural decision making. Further effects were discussed by Kahneman and Tversky (1974), e.g. adjustments, anchoring, or frames, but will not discussed in this paper. Many ideas were based on these fundamental theories and contributed a lot to this scientific field.

Decision process in organizations. The decision making process in organizations is made by humans and hence reflects human behaviour in orgnanizations. March and Simon (1993) grouped this in three classes: 
(1) Organization members are primarily passive instruments; performing their work and accepting direction, but not initiating actions.

(2) Organization members bring their own attitudes, values, and goals into the organization.

(3) Organization members are decision makers and problem solvers.

This classification refers to a different type of decisions in organizations, hence a robust process must enable decision making and decision execution, over the varied layers in an organization.

Therefore, it is important to understand the decision process in organizations. The theoretical process is rational designed (Laux et al., 2014):

(1) Problem definition: a decision maker realises that a situation is not satisfactory.

(2) Specification of the target system: targets will be formulated for the defined goal.

(3) Investigation of possible action alternatives: search, analysis, and prognosis for alternatives are designed, collected, calculated, and analysed.

(4) Choice of an alternative: based on the target system, the best alternative should be chosen.

(5) Decision in the realization phase: still while realizing the alternative, decisions have to be made and followed up.

Following this process, the maximum utility for the decision will be made. But the main question is, if in an organization, this strict process will be executed. As Simon (1997) explained: "all decision is a matter of compromise". In an organization with different interests of members, the question of a maximum utility for the decision problem is to be questioned. In an organization, there is never a perfect achievement of targets reachable. The environment of the organization limits the alternatives and the maximum of utility (Simon, 1997).

Further questions will be raised in today's business world with an increase of a democratic leadership style, that for decisions committees are installed. The set up of a committee is quite important and all restrictions have to be taken into consideration, e.g. information asymmetries in different areas (Bamberg et al., 2012).

This opposite view to a rational decision process raises the question how the decision process in organizations is really made. Are organizations as rational as expected or are there emotional driven which has effects on decisions. The behavioural influence in organizations has to be respected and the result is based on this set up (March \& Simon, 1993).

\section{Globalization and Digitalization}

Globalization. Globalization is the international integration arising from the interchange of world views, products, ideas, and other aspects of culture.

Globalization is a process of interaction and integration among the people, companies, and governments of different nations, and a process driven by international trade and investment and aided by information technology. This process has effects on the environment, on culture, on political systems, on economic development and prosperity, and on human physical well-being in societies around the world. (Albrow \& King, 1990)

The global phenomenon of business technology diffusion is worth to analyze in detail. For the paper, this particular part of globalization is in scope-digitalization.

\section{Digitalization.}

Digitalization refers to the practice of taking processes, content or objects that used to be primarily (or entirely) physical or analogue and transforming them to be primarily (or entirely) digital. The effect of digitizing processes, aside 
from potential efficiency gains, is to make processes more tailorable and malleable. (Fichman, Dos Santos, \& Zheng, 2014)

Not only based on data, moreover targeted on markets, organizations and processes digitalization will deploy its full value to businesses and industries. The new era of digitalization has started already and shows today a first step of a new business world with a change in division of work. In the early 20th century, a "computer" was an employee calculating tables the whole day. In a first step, an automated computer (as understand today) took over this task and increased quality and efficiency of this process. Since then, the automation of world was ongoing and influenced by computers and machines. Important for the development was the definition of rules for computers, because computers are perfect in following algorithmic rules. (Brynjolfsson \& McAfee, 2014). Further actions took place to develop more feasibilities of machines, i.e. Apple iPhone is now with the software Siri able to understand and direct the user. This is a real quantum leap, because to automatize language and transfer this into instructions was a giant step change for the industry. Currently, the speed of development is increasing, either the trend of "Industry 4.0" with full automation of the production flow (Zelinski, 2016) or "artificial intelligence" that robots tend to make autonomous decisions and developed self-awareness and self-maintenance (Lee, Kao, \& Yang, 2014). Robots and machines are striving into working environment and will strongly replace human work. The balance of division on work changed already but will change dramatically in the future, though traditional professions will disappear, but new professions will appear. To close the loop of digitalization and globalization means, a global business process only can be managed successfully, if a proper digital support is in place, e.g. automated warehousing or supply chain management.

Referring to the effects of digitalization on decision making, this trend will completely change the way of making decisions. Flexibility and transformability are key attitudes of successful organizations in the future and drive them on the road of digitalization (Bauer, Hämmerle, Schlund, \& Vocke, 2015). Digitalization will have an effect on customer structure, increase the efficiency of operations, and at the end change the entire business model (Westerman, Bonnet, \& McAfee, 2014).

Four levers of transformation have to be in scope of the decision maker (BDI, 2015):

(1) Digital data (big data): recording, processing, and analysis of mass data will enable more predictable forecasts and decisions.

(2) Automation: the combination of traditional work and artificial intelligence will enable autonomous work in self-organization systems with high quality and high efficiency.

(3) Integration: connection of the entire value chain will enable synchronized supply chains with shorter production cycles and faster innovation (mobile or fiber opic net).

(4) Digital customer access: new competitors, new services, and new transparency will increase competition.

\section{Digitalization Implications on Decision Making}

Described above, the digitalization of businesses and organizations will dramatically change decisions with all related circumstances. The decision making process will be stepwise automated, hence, machines will make choices. In the past, this scenario was unthinkable, because independent machine decisions are under big criticism. But today's world shows that machines make decisions for humans, e.g. in current cars, lots of electronic systems help to drive the car, like anti-lock braking systems or intelligent speed assistance systems. 
In the next step, an autonomous driving car will be designed and produced for real driving, as mentioned in the introduction. Today, earmarked and specialized machines are status quo, but in the future all-purpose, robots will replace these machines (Brynjolfsson \& McAfee, 2014).

A movement of an organization toward digitalization is necessary to survive in today's business environment, because digitalization changes the processes and the structures of organizations. Market conditions, as customer structure or competition will change completely due to influences of technology and new devices. Production methods are tremendously influenced by digital innovations and new production processes; 3D printer as well as the usage of smart applications are changing the entire production flow. Close to production, supply structures are evolving stepwise toward high quality and high efficiency. Collaboration in and between organizations are more important than ever to enable an efficient flow in the supply chain.

In a survey, Westerman et al. (2014) described organizations, which transformed their business model toward a digital organization (Digirati). Revenue and profit of these organizations increased compared to the industry benchmark. These "digital masters" realize $+26 \%$ more profit and $+9 \%$ higher revenue (184 companies out of their study from 391 companies), from their physical assets, compared to their industry peers (Westerman \& McAffee, 2012). To really understand the analysis of this survey, the structure of the model seems to be important; key for an organizational development is to main capabilities, digital, and leadership capability. The model is designed on the x-axis with "leadership capability" and on the y-axis with "digital capability" and shows the development stage of organizations in term of their digital leadership status.

This paper is focussing on decision making, hence a view on an automation of decision has to be analysed. In Table 1, the development of decisions is illustrated. In the past, the decision process was typically an administrative task of managers and consequently human based, with all emotional influences. The development over time shows a trend towards a decision making automation, based on the capabilities of machines. In the future, more sophisticated machines and artificial intelligence will be used by the decision maker for businesses.

Table 1

Development Over Time of Decision Making

\begin{tabular}{|l|l|l|l|}
\hline Decision conditions & Past & Today & Future \\
\hline Decision under certainty & human & automated & automated \\
\hline Decision under risk & human & automation started & automated \\
\hline Decision under uncertainty & human & human & partly automated \\
\hline
\end{tabular}

Source: author's construction.

Supported by digital data and creating the opportunity to get massive volumes of data (big data) recorded and processed in an robust process, the analysis and usage of these data will enable organizations to create a rational decision process to reach maximum utility (von Neumann \& Morgenstern, 2004).

Automation of workforce by robots and artificial intelligence with autonomous processes in a self-organizing system will improve decisions on a rational level. In a real-time manner, intelligent machines are able to make fast decisions with a precise result.

In the next level of integration on an inter-organizational view, data flow will ensure the real-time communication of systems with an efficiency gain for all participants (win-win situation). Decisions are made based on algorithmic logic and strive toward maximum utility. 
New customer access, with a lot of relevant customer data, will enable organizations to create a customized offer per each customer, i.e. a tailor-made solution with services and new products.

\section{Conclusion}

Starting from a financial point of view, digitalization will enable higher profits and revenues, hence a focus on this trend seems obvious. Especially the process of decision making is for an organization from an elementary attitude to manage their business. After analyzing the theoretical background of decision making, two opposite theories of rational view, as von Neumann and Morgenstern (2004) described the game theory to reach maximum utility and to analyze the psychological view of decision making, explained by Kahneman and Tversky (1974) with a huge participation of system 1, with spontaneous respond to decisions, currently, a new paradigm occurs. The theoretical homo oeconomicus, which was over decades in the economic science as an exemplary agent for utility maximization seems now becoming reality, but in form of automated decisions in the era of digitalization. Automation of processes with self-organizing systems has a clear algorithmic structure, this logical structure will be followed by the system. That means, homo oeconomicus will be reality for the first time, by recording, processing, and analyzing all relevant data and drawing autonomous decisions to reach maximum utility. This step changing process will increase efficiency and profitability of organizations. As a result, utility maximization seems first time reachable with a win-win situation for customers and organizations. Based on these rules, no human error probability will occur in organizations; at the end, it is a "digital oeconomicus".

\section{References}

Albrow, M., \& King, E. (1990). Globalization, knowledge and society. London: SAGE.

Bamberg, G., Coenenberg, A., \& Krapp, M. (2012). Betriebswirtschaftliche Entscheidungslehre. München: Verlag Franz Vahlen.

Bauer, W., Hämmerle, M., Schlund, S., \& Vocke, C. (2015). Transforming to a hyper-connected society and economy-Towards an "Industry 4.0". Science direct, procedia manufacturing (pp. 417-424). Elsevier.

BDI (Bundesverband der deutschen Industrie) Research. (2015). Die digitale Transformation der Industrie.

Brynjolfsson, E., \& McAfee, A. (2014). The second machine age. New York: W.W. Norton \& Company.

Buchanan, L., \& O'Connell, A. (2006). A brief history of decision making. Harvard Business ReviewEnvironment. Science Direct, Procedia CIRP, 16, 3-8.

Fichman, R., Dos Santos, B., \& Zheng, Z. (2014). Digital innovation as a fundamental and powerful concept in the information systems curriculum. MIS Quarterly, 38(2), 329-353.

Kahneman, D., \& Tversky, A. (1974). Judgment under uncertainty: Heuristics and biases. Science, New Series, 184.

Kahneman, D. (2011). Thinking, fast and slow. UK: Penguin Random House.

Laux, H., Gillenkirch, R., \& Schenk-Mathes, H. (2014). Entscheidungs theorie. Berlin; Heidelberg: Springer Verlag.

Lee, J., Kao, H., \& Yang, S. (2014). Service innovation and smart analytics for Industry 4.0 and big data.

March, J., \& Simon, H. A. (1993). Organizations. Cambrigde and Oxford: Blackwell.

Simon, H. A. (1997). Administrative behaviour. New York: The Free Press.

Spath, D. (2013). Produktionsarbeit der Zukunft-Ndustrie 4.0. Fraunhofer IAO; Stuttgart, Fraunhofer IRB-Verlag The Levin Institute. Retrieved from http://www.globalization101.org

von Neumann, J., \& Morgenstern, O. (2004). Theory of games and economic behaviour. Princeton: University Press.

Westerman, G., Bonnet, D., \& McAfee, A. (2014). Leading digital. Boston: Harvard Business School Publishing.

Westerman, G., \& McAfee, A. (2012). The digital advantage: How digital leaders outperform their peers in every industry. Research Brief. The MIT Center for Digital Business.

Wilenius, M. (2014). Leadership in the sixth wave-Excursions into the new paradigm of the Kondratieff cycle 2010-2050. Eur J Futures Res. Springerlink.com

Zelinski, P. (2016). Where 4.0 might go. Retrieved from http://www.mmsonline.com/ 